\title{
Factors Affecting Maternal Coping in Korean Mothers of Children with Cancer
}

\author{
Shanzida Khatun ${ }^{1}$, Hee Soon Kim ${ }^{1,2 *}$, Hyun-Bong Park ${ }^{1}$ \\ ${ }^{1}$ College of Nursing, Yonsei University, Seoul, South Korea \\ ${ }^{2}$ Mo-Im Kim Nursing Research Institute, Seoul, South Korea \\ Email: *khssoon@yuhs.ac
}

How to cite this paper: Khatun, S., Kim, H.S. and Park, H.-B. (2016) Factors Affecting Maternal Coping in Korean Mothers of Children with Cancer. Open Journal of Nursing, 6, 751-766.

http://dx.doi.org/10.4236/ojn.2016.69076

Received: August 2, 2016

Accepted: September 18, 2016

Published: September 21, 2016

Copyright $\odot 2016$ by authors and Scientific Research Publishing Inc. This work is licensed under the Creative Commons Attribution International License (CC BY 4.0).

http://creativecommons.org/licenses/by/4.0/

\begin{abstract}
Background: The childhood cancer is increasing throughout the world. The incidence of children and adolescent ( 1 - 19 years old) mortality by cancer was 4.49 by 2006 (Korea Statistics, 2014). Mothers of children experienced a difficult situation in coping when their children were diagnosed with cancer. Based on Mishel's Uncertainty in Illness Theory, maternal uncertainty and perceived social support are important factors that may have an impact on maternal coping in mothers of children with cancer. Therefore, it was worth to investigate this phenomenon in the context of Korea where no such study was conducted. Objective: To identify the factors affecting maternal coping in mothers of children with cancer. Methods: The study was conducted by using a descriptive design. This study was approved by the Institutional Review Board, Yonsei Health System, Severance Hospital, Seoul, Korea and informed consent forms were obtained from the participants. Fifty-nine mothers completed three questionnaires: 1) Parent's Perception of Uncertainty Scale, 2) Multidimensional Scale of Perceived Social Support, and 3) Coping Health Inventory for Parents. The internal consistency of these instruments was satisfactory, all with alpha coefficients over 0.86. Results: Hierarchical multiple regression analysis revealed that perceived social support and maternal uncertainty together explained $35 \%$ of the variance in the maternal coping in mothers of children with cancer $\left(\mathrm{R}^{2}=0.353, \mathrm{~F}=15.255, \mathrm{p}=\right.$ 0.000). Perceived social support and maternal uncertainty had an impact on maternal coping. Conclusions: The findings provided information that could be used in a further intervention study to increase maternal coping in mothers of children with cancer.
\end{abstract}

\section{Keywords}

Coping, Factors, Mothers, Children, Cancer 


\section{Introduction}

The childhood cancer is a devastating disease. Globally, approximately 163,300 children develop cancer each year [1] and $84 \%$ of these children live in developing countries [2]. In Korea, the annual incidence of cancer in children and adolescents was 1700 in 20012005 [3]. The rate of child (under 5) mortality is 3.4/1000 live births [4]. From 2011 to 2014, there were 7.8 million children and adolescents who were diagnosed as cancer in Bangladesh [5].

Studies indicated that children with cancer experienced a loss of hair [6], pain, social rejection of peers [7], anxiety and depression [8], and behavioral disturbances [9]. In addition, parenting a child with cancer is very distressing, with parents reporting a sense of loss of control, stress, anxiety, depression, sleep disturbance, and uncertainty [10], despair followed by fear and guilt [11] [12], feelings of hopelessness [13], poor psychological well-being [14], and feeling deprived of a context of normality [15]. More specifically, childhood cancer can cause a great deal of physical and emotional stress on mothers [16]. Some Korean and Bangladeshi mothers believed that chronic illnesses like cancer were a type of fate and punishment or a curse from God [15] [17]. A study of Martinson et al. [11] found that Korean mothers of children with cancer felt guilty when they did not receive adequate support from their relatives.

A number of factors contributed to maternal coping in response to stressful events. Studies confirmed that education levels were positively correlated with an active coping style [17]-[19]. The age of both fathers and children and the length of time since diagnosis showed direct correlations to paternal uncertainty and coping [20]. Besides these factors, two significant factors contributing to maternal coping are uncertainty and perceived social support, based on Mishel's Uncertainty in Illness Theory (MUI) [21].

Bowers [22] found that uncertainty had a direct effect on emotion-focused coping, regardless of the appraisal of the uncertainty as danger or opportunity. "Chronicity and uncertainty" are responsible for both perceived stress and coping strategies [23]. Another study revealed that parents of young children with chronic conditions with intermittently unpredictable symptoms reported significantly more distress than parents of children with more predictable symptoms [24]. However, a study by Lee, Yoo, and Yoo [25] found that parenting stress was related to ambiguity, lack of clarity, and lack of information, but not related to unpredictability. A study by Bowers [22] found that social support was significantly associated with danger and opportunity. Perceived social support contributed to parental distress [26], stress [25] [27] [28], and maternal psychological adjustment [29] [30]. Martinson et al. [11] identified that most Korean mothers received support from their spouse, physicians, nurses, family, neighbors, friends, and religious practitioners. However, social support did not demonstrate any potential effect on mothers' distress 5 years after their child's diagnosis with cancer (T4) [31].

Although there have been many studies as assessing psychological adjustment and coping for parents of children with cancer, relatively few have highlighted the cognitive state of uncertainty and illness-related distress, and social support were associated with 
maternal coping. Moreover, previously published studies were conducted using diverse families from different cultures, and presented inconsistent findings. In addition, in the existing literature, there are no studies on maternal uncertainty, social support, and maternal coping based on Mishel's Uncertainty theory. Therefore, it is necessary to investigate factors affecting maternal coping among mothers of children with cancer. Information obtained from this study can guide interventions for pediatric oncology nurses to help mothers manage uncertainty and enhance effective coping when their child is diagnosed with cancer.

\section{Conceptual Framework}

The conceptual framework of this study was guided by the Uncertainty in Illness Theory (UIT) [21]. The theory proposes that uncertainty exists in illness situations that are ambiguous, complex, and unpredictable. The theory explains how individuals cognitively process illness-related stimuli and how they structure meaning around those events [21]. The theory focuses on the ill individual and the parent or family of that individual. According to the UIT, "uncertainty is the inability to determine the meaning of illness-related events, occurring when the decision maker is unable to assign definite value to objects or events, or is unable to predict outcomes accurately" [21]. It is a cognitive state created when an individual cannot adequately structure or categorize an illness event because of insufficient signals [21]. In this study, maternal uncertainty can be defined as the inability of the decision maker (the mother) to adequately structure, categorize, and determine the meaning of illness-related events. Structure providers, such as social support, influence uncertainty, directly or indirectly. Social support directly influences uncertainty by providing information and guidance to temper ambiguity, complexity, lack of information, and unpredictability [21]. In this study, perceived social support is the mother's perception of whether she receives adequate support from family, friends, and significant others. Maternal coping is an outcome variable in this study. Maternal coping is the specific effort, both behavioral and psychological, that mothers employ to master, tolerate, and reduce stressful events. According to this theory, the researchers assume that maternal coping can be predicted by maternal uncertainty and perceived social support. Figure 1 is the conceptual framework of this study (Figure 1).

\section{Methods}

\subsection{Setting and Participants}

Participants were recruited from a single health center in Korea. The mothers in this study were the primary caregiver of their children. The study was conducted from December 2013 to April 2014 at inpatient and outpatient departments for children's care delivery. The sample size in this study was estimated by using statistical power analysis. Using G-power 3.13 for multiple linear regression analysis $80 \%$ power was produced with 58 participants with a medium effect size $\left(f^{2}=0.25\right)$ and $\alpha=0.05$ (Cohen, 1988). However, the final sample for this study consisted of 59 mothers of children with can- 


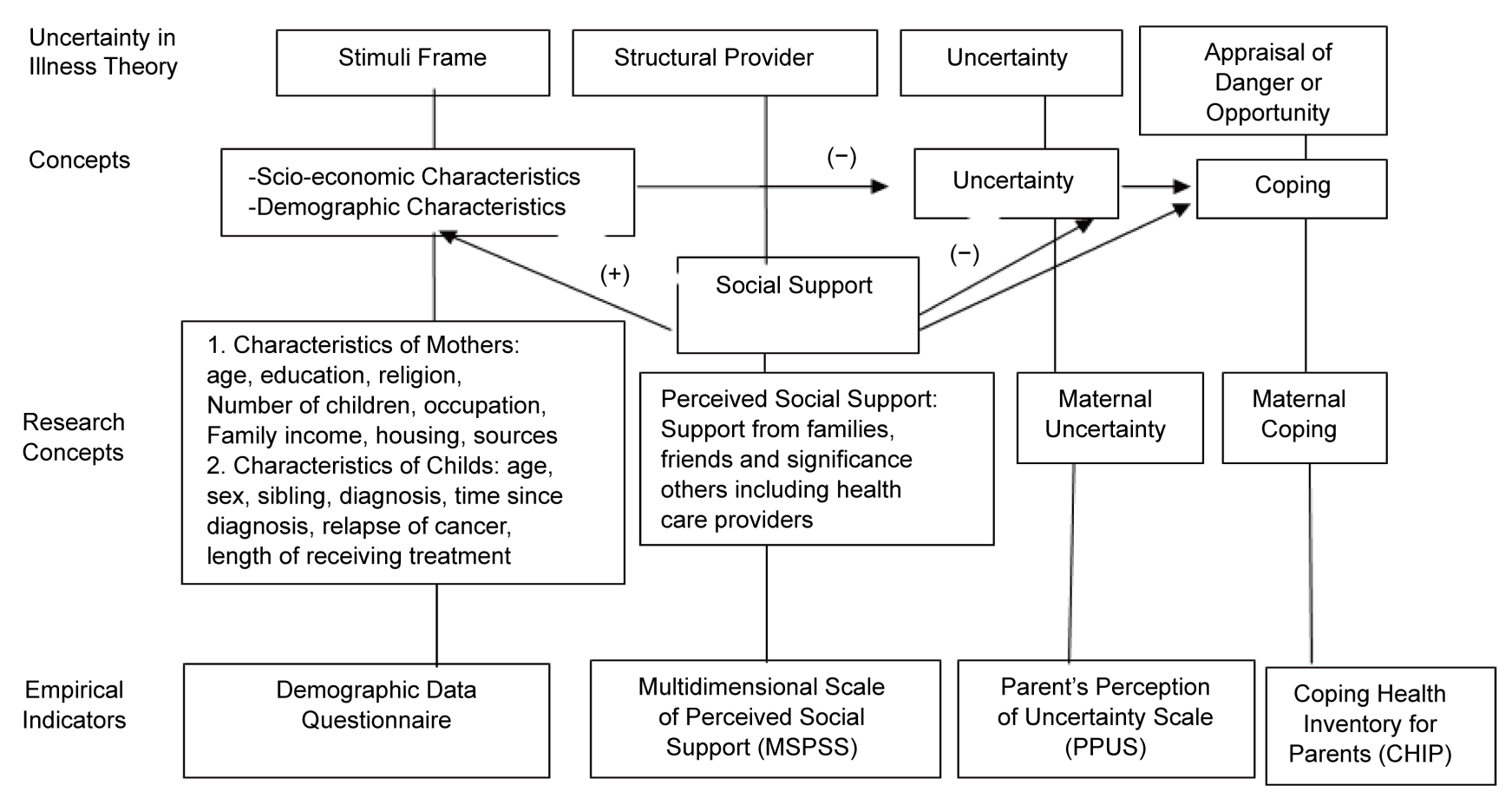

Figure 1. Conceptual framework of the study.

cer. A purposive sample of mothers was invited to complete the self-report questionnaire after the research study was announced by doctors. All mothers met the following inclusion criteria: 1) have adequate perception to person and place; 2) able to understand and speak Korean; 3 ) have a child aged 2 - 6 years old who was admitted to the hospital with a cancer diagnosis (and no additional diagnoses at least 1 month prior to the study); and 4) the child with a cancer diagnosis was undergoing treatment. Multicultural mothers were excluded from this study.

\subsection{Ethical Considerations}

This research was approved by Institutional Review Board, Yonsei Health System, Severance Hospital, 50-1, Yonseiro, Seodaemungu, Seoul, Korea and Yonsei Cancer Center, Yonsei Health System, Severance Hospital, 50-1, Yonseiro, Seodaemungu, Seoul, Korea. Written consent form obtained from the mothers. All mothers were informed about the study purposes and methods. A small gift was given to the participants as compensation.

\subsection{Measures}

Data were collected by using four questionnaires: 1) Demographic Data Questionnaire, 2) Parent's Perception of Uncertainty Scale (PPUS), 3) Multidimensional Scale of Perceived Social Support (MSPSS), and 4) Coping Health Inventory for Parents (CHIP).

\subsection{The Demographic Data Questionnaire}

The Demographic Data Questionnaire was designed by the researcher based on the li- 
terature reviewed. The characteristics of mothers consisted of age, education, religion, number of children, occupation, monthly family income, and housing status. The characteristics of children consisted of age, sex, siblings, diagnosis, time since diagnosis, relapse of cancer, and the duration of treatment.

\subsection{PPUS}

Maternal uncertainty was measured using the PPUS. The original items of the PPUS [32] were derived from Mishel's Uncertainty in Illness Scale for Adults (MUIS-A). The PPUS consists of 31items with four subscales: ambiguity (13 items), lack of clarity (9 items), lack of information (5 items), and unpredictability (4 items). All items were on 4-point Likert-type scale, ranging from strongly disagree (1) to strongly agree (4). The range of possible scores on the 31-items PPUS is 31 to 124, with a higher score indicating greater uncertainty. The Cronbach's alpha of the total PPUS was 0.86 [32] for the Korean version, the Cronbach's alpha was 0.86 [25].

\subsection{MSPSS}

Perceived social support was measured using the MSPSS [33]. The MSPSS consists of 12items with three domains: support from family (4items), friends (4items), and from a significant other (4items). All items were on a 5-point Likert-type scale, ranging from strongly disagree (1) to strongly agree (5). Total and subscale scores range from 1 - 5, with higher scores suggesting greater levels of perceived social support. The alpha coefficient for the total scale was 0.93 [34]; for the Korean version, the Cronbach's alpha was 0.85 [35].

\subsection{CHIP}

Maternal coping was measured by using the CHIP [36], which assesses parents' appraisal of behaviors they use to manage their family life when they have a child who is seriously and/or chronically ill. The CHIP consists of 45 items. In this study, 36 items were used with three subscales: efforts for an optimistic definition of the situation (16 items), efforts for emotional stability ( 15 items), and efforts to resolve the problem (5 items). All items were scored on a 4-point Likert-type scale, ranging from strongly disagree (1) to strongly agree (4). The range of possible scores on the 36-item CHIP was 36 to 120 , with a higher score indicating greater maternal coping. The overall reliability coefficient was 0.88 [36]. This instrument was back translated and revised into a Korean version by Sung (2003). The Cronbach's alpha for the 36-item scale was 0.92 [37].

\subsection{Data Collection}

A descriptive approach was used. Data were collected through self-report questionnaires. After getting permission from the Director of the Yonsei Cancer Center, the research assistant met with the nurse manager of the selected ward and the participants who met the inclusion criteria. The research assistant introduced herself and briefly explained the purpose of the study. The research assistant explained informed consent 
and that mother had a right to refuse to participate in the study at any time. The research assistant asked participants to provide answers in accordance with the questions being asked. The interview time ranged from 30 - 40 minutes. The research assistant checked the completeness of the questionnaires. The data were collected from November2014 to January 2015.

\subsection{Data Analysis}

Both descriptive and inferential statistics were used to analyze the data. Descriptive statistics were used to analyze the characteristics of mothers and their children. The differences between characteristics and maternal coping were analyzed using T-tests and one-way analyses of variance. The relationships between maternal uncertainty, perceived social support, and maternal coping were analyzed using Pearson's Product Moment correlation coefficients. A hierarchical multiple regression model was used to analyze if maternal uncertainty and perceived social support can predict maternal coping in mothers of children with cancer.

\section{Results}

\subsection{Participants}

Fifty-nine mothers of children with cancer with a mean age of $35.34 \pm 4.68$ years (range, 21 - 46) participated in this study. More than half of the mothers had a college education (59.3\%) and a majority were religious (69.5\%). A majority of mothers had more than two children (69.8\%). A large number of mothers had no paid employment (83.1\%), however, the average monthly family income was $527.55 \pm 463.31$ million Korean Won. Half of the mothers did not own their homes (instead, rented or leased a home). A majority of mothers got information from their health care providers (64.4\%) (Table 1).

\subsection{Characteristics of Children}

The average age of children was $4.27 \pm 1.59$ years old. Thirty-five (59.3\%) children were male and a majority had a sibling (69.5\%). Approximately $55.9 \%$ children had solid cancer (brain tumor, neuroblastoma) and others types of cancer. The mean time since diagnosis was $2.29 \pm 0.87$ years and a large number of children had not relapse condition $(76.3 \%)$. The average treatment period was $18.68 \pm 1.11$ months (Table 2).

\subsection{Maternal Uncertainty, Perceived Social Support, and Maternal Coping}

Table 3 shows that the descriptive statistics of each independent variable and the dependent variable. The mean of the maternal uncertainty was $67.03(\mathrm{SD}=9.92)$; scores ranged from 46 to 87 . The mean of the ambiguity subscale was $28.03(\mathrm{SD}=5.41)$ and scores of this subscale ranged from 15 to 36 . The mean of the lack of clarity subscale was $19.02(\mathrm{SD}=2.91)$ and scores ranged from 11 to 24 . The average of the lack of information subscale was $10.31(\mathrm{SD}=1.90)$ and scores ranged from 5 to 14 . The mean of 
Table 1. General characteristics of mothers $(N=59)$.

\begin{tabular}{|c|c|c|c|c|}
\hline Characteristics & Categories & $\mathrm{n}$ & $\%$ & $\mathrm{M} \pm \mathrm{SD}$ \\
\hline \multirow[t]{2}{*}{ Age (yrs) } & $<35$ & 24 & 40.7 & $35.34 \pm 4.68$ \\
\hline & $\geq 35$ & 35 & 59.3 & \\
\hline \multirow[t]{3}{*}{ Education level } & Less than college & 8 & 13.6 & \\
\hline & Vocational & 16 & 27.1 & \\
\hline & College or more & 35 & 59.3 & \\
\hline \multirow[t]{2}{*}{ Religion } & Religion & 41 & 69.5 & \\
\hline & No religion & 18 & 30.5 & \\
\hline \multirow[t]{2}{*}{ Number of children } & 1 & 18 & 30.5 & $1.85 \pm 0.69$ \\
\hline & $\geq 2$ & 41 & 69.8 & \\
\hline \multirow[t]{2}{*}{ Employment status } & Employed & 10 & 16.9 & \\
\hline & Unemployed & 49 & 83.1 & \\
\hline \multirow[t]{3}{*}{ Monthly income (Won) } & $<4$ million & 32 & 54.2 & $527.55 \pm 463.31$ \\
\hline & $\geq 4$ million & 21 & 35.6 & \\
\hline & Missing & 6 & 10.2 & \\
\hline \multirow[t]{2}{*}{ Housing } & Own house & 29 & 49.2 & \\
\hline & Other & 30 & 50.8 & \\
\hline \multirow[t]{2}{*}{ Information from health provider } & Yes & 38 & 64.4 & \\
\hline & No & 21 & 35.6 & \\
\hline
\end{tabular}

Table 2. General characteristics of children $(N=59)$.

\begin{tabular}{ccccc}
\hline Characteristics & Categories & N & $\%$ & M \pm SD \\
\hline Age (yrs) & $2-3$ & 21 & 35.6 & $4.27 \pm 1.59$ \\
Sex & $4-6$ & 38 & 64.4 & \\
Mabling & Female & 35 & 59.3 & \\
& Yes & 41 & 40.7 & \\
Diagnosis & No & 18 & 30.5 & \\
& Leukemia & 26 & 44.1 & $2.29 \pm 0.87$ \\
Time since diagnosis & Solid cancer & 33 & 55.9 & \\
& $<1$ year & 26 & 44.1 & \\
Relapse of cancer & $\geq 1$ yrs & 33 & 55.9 & \\
& Yes & 14 & 23.7 & \\
Treatment duration & No & 45 & 76.3 & \\
& $<1$ year & 28 & 47.5 & \\
& $\geq 1$ yrs & 31 & 52.5 & \\
\hline
\end{tabular}


Table 3. Descriptive statistics of maternal uncertainty, perceived social support, and maternal coping in mothers of children with cancer $(N=59)$.

\begin{tabular}{|c|c|c|c|c|}
\hline \multirow{2}{*}{ Variable } & \multirow{2}{*}{ Categories } & \multicolumn{2}{|c|}{$\mathrm{M} \pm \mathrm{SD}$} & \multirow{2}{*}{ Range } \\
\hline & & Total & Item & \\
\hline \multirow{5}{*}{ Maternal Uncertainty } & Total maternal uncertainty & $67.03 \pm 9.92$ & $2.16 \pm 0.32$ & $46-87$ \\
\hline & Ambiguity & $28.03 \pm 5.41$ & $2.16 \pm 0.42$ & $15-36$ \\
\hline & Lack of clarity & $19.02 \pm 2.91$ & $2.11 \pm 0.32$ & $11-24$ \\
\hline & Lack of information & $10.31 \pm 1.90$ & $2.06 \pm 0.38$ & $5-14$ \\
\hline & Unpredictability & $9.68 \pm 1.66$ & $2.42 \pm 0.41$ & $7-14$ \\
\hline \multirow{4}{*}{$\begin{array}{l}\text { Perceived Social } \\
\text { Support }\end{array}$} & Total perceived social support & $46.22 \pm 6.31$ & $3.85 \pm 0.52$ & $29-60$ \\
\hline & Support from family & $16.81 \pm 2.50$ & $4.20 \pm 0.62$ & $8-20$ \\
\hline & Support from friends & $15.25 \pm 2.63$ & $3.81 \pm 0.66$ & $4-20$ \\
\hline & Support from significant others & $14.15 \pm 3.16$ & $3.53 \pm 0.79$ & $7-20$ \\
\hline \multirow{4}{*}{ Maternal Coping } & Total maternal coping & $104.73 \pm 11.72$ & $2.91 \pm 0.32$ & $77-137$ \\
\hline & $\begin{array}{l}\text { Effort for optimistic definition of the } \\
\text { situation }\end{array}$ & $49.08 \pm 5.69$ & $3.06 \pm 0.35$ & $38-62$ \\
\hline & Effort for emotional stability & $40.12 \pm 7.50$ & $2.67 \pm 0.5$ & $25-70$ \\
\hline & Effort to resolve the problem & $15.53 \pm 2.17$ & $3.10 \pm 0.43$ & $10-20$ \\
\hline
\end{tabular}

the unpredictability subscale was $9.68(\mathrm{SD}=1.66)$ and scores ranged from 7 to 14 . The mean of the perceived social support scale was $46.22(\mathrm{SD}=6.31)$ and scores ranged from 29 to 60 . The mean of the support from family subscale was $16.81(\mathrm{SD}=2.50)$ and scores ranged from 8 to 20 . The mean of the support from friends subscale was 15.25 $(\mathrm{SD}=2.63)$ and scores ranged from 4 to 20 . The mean of the support from significant others subscale was 14.15 ( $\mathrm{SD}=3.16$ ) and scores ranged from 7 to 20 . The average of the maternal coping score was $104.73(\mathrm{SD}=11.72)$ and scores ranged from 77 to 137. The mean of the effort for optimistic definition of the situation subscale was 49.08 (SD $=5.69$ ) and scores ranged from 38 to 62 . The mean of the effort for emotional stability subscale was $40.12(\mathrm{SD}=7.50)$ and scores ranged from 25 to 70 . The mean of the effort to resolve the problem was $15.53(\mathrm{SD}=2.17)$ and scores ranged from 10 to 20 .

\subsection{Differences in Maternal Uncertainty, Perceived Social Support, Maternal Coping and Demographic Characteristics of Mothers and Their Children}

Table 4 and Table 5 show the differences in maternal uncertainty, perceived social support, maternal coping and characteristics of mothers and their children. Maternal uncertainty was statistically significantly different by maternal education $(t=4.004, \mathrm{p}=$ $0.024)$ and by the child's relapse status $(t=2.826, \mathrm{p}=0.006)$. There was a statistically significant difference in perceived social support based on a mother's employment status $(t=2.390, \mathrm{p}=0.020)$. Maternal coping also significantly varied based on maternal employment status $(t=2.258, \mathrm{p}=0.028)$. 
Table 4. Differences in maternal uncertainty, perceived social support, and maternal coping in mothers of children with cancer according to demographic characteristics $(N=59)$.

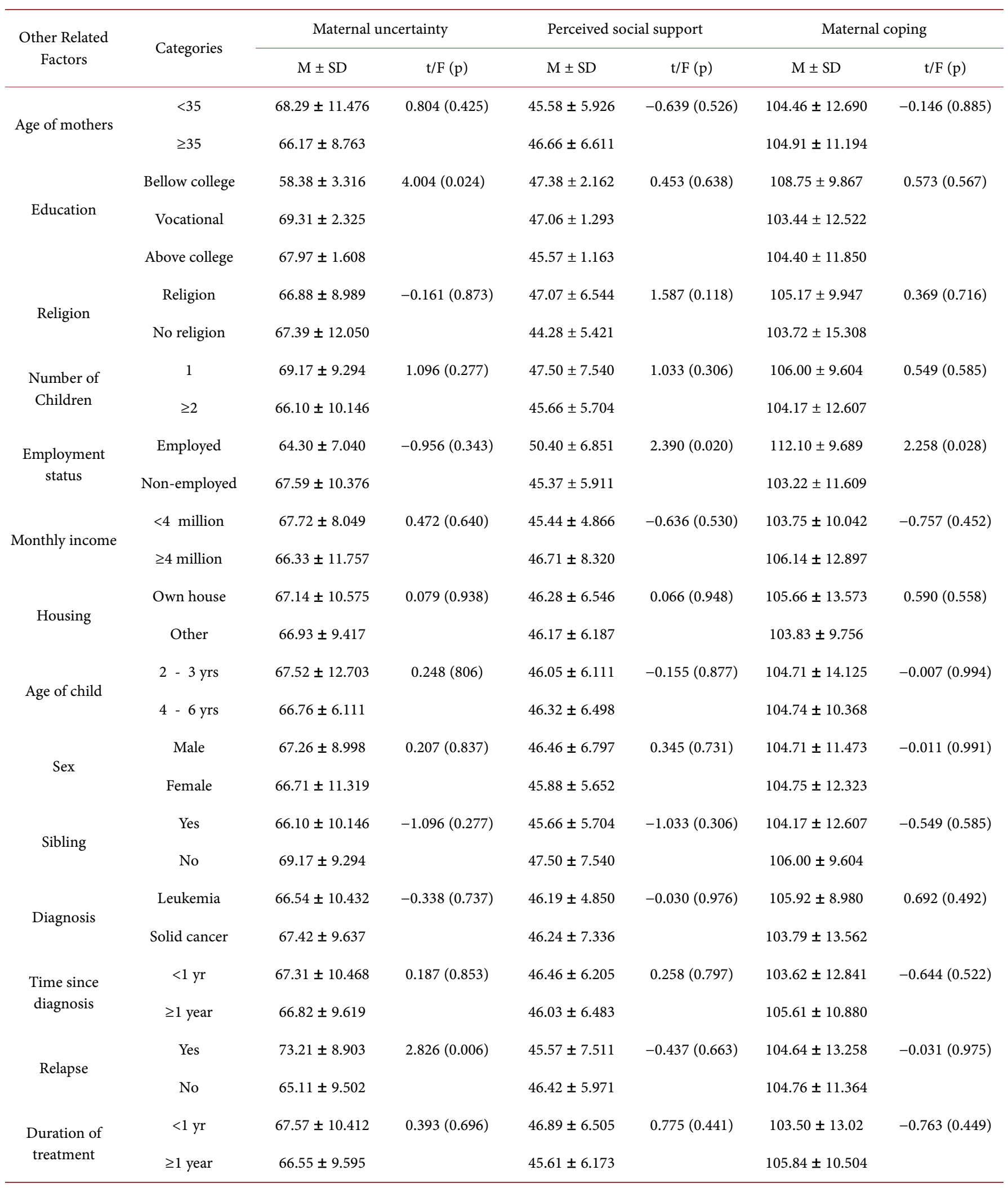


Table 5. Descriptive statistics independent t-tests, and ANOVAs among characteristics of mothers and their children and maternal coping in mothers of children with cancer $(N=59)$.

\begin{tabular}{|c|c|c|c|c|c|c|c|c|c|}
\hline \multirow{2}{*}{$\begin{array}{l}\text { Other } \\
\text { Related } \\
\text { Factors }\end{array}$} & \multirow[t]{2}{*}{ Categories } & \multicolumn{2}{|c|}{ Total Maternal Coping } & \multicolumn{2}{|c|}{$\begin{array}{c}\text { Maternal Coping } \\
\text { (Effort for optimistic } \\
\text { definition of the situation) }\end{array}$} & \multicolumn{2}{|c|}{$\begin{array}{l}\text { Maternal Coping (Effort for } \\
\text { emotional stability) }\end{array}$} & \multicolumn{2}{|c|}{$\begin{array}{l}\text { Maternal Coping (Effort to } \\
\text { resolve the problem) }\end{array}$} \\
\hline & & $\mathrm{M} \pm \mathrm{SD}$ & $\mathrm{t} / \mathrm{F}(\mathrm{p})$ & $\mathrm{M} \pm \mathrm{SD}$ & $\mathrm{t} / \mathrm{F}(\mathrm{p})$ & $\mathrm{M} \pm \mathrm{SD}$ & $\mathrm{t} / \mathrm{F}(\mathrm{p})$ & $\mathrm{M} \pm \mathrm{SD}$ & $\mathrm{t} / \mathrm{F}(\mathrm{p})$ \\
\hline \multirow{2}{*}{$\begin{array}{l}\text { Age of } \\
\text { mother }\end{array}$} & $<35$ & $104.46 \pm 12.690$ & $-0.146(0.885)$ & $48.08 \pm 5.725$ & $-1.122(0.267)$ & $40.42 \pm 10.017$ & $0.251(0.803)$ & $15.96 \pm 2.053$ & $1.277(0.207)$ \\
\hline & $\geq 35$ & $104.91 \pm 11.194$ & & $49.77 \pm 5.647$ & & $39.91 \pm 5.294$ & & $15.23 \pm 2.224$ & \\
\hline \multirow{3}{*}{ Education } & Bellow college & $108.75 \pm 9.867$ & $0.573(0.567)$ & $53.00 \pm 5.099$ & $2.536(0.088)$ & $39.88 \pm 5.249$ & $0.523(0.596)$ & $15.88 \pm 2.696$ & $0.17(0.841)$ \\
\hline & Vocational & $103.44 \pm 12.522$ & & $49.25 \pm 6.309$ & & $38.56 \pm 6.491$ & & $15.63 \pm 1.708$ & \\
\hline & Above college & $104.40 \pm 11.850$ & & $48.11 \pm 5.268$ & & $40.89 \pm 8.366$ & & $15.40 \pm 2.278$ & \\
\hline \multirow{2}{*}{ Religion } & Religion & $105.17 \pm 9.947$ & $0.369(0.716)$ & $49.63 \pm 5.276$ & $1.122(0.267)$ & $40.12 \pm 6.435$ & $0.005(0.996)$ & $15.41 \pm 2.377$ & $-0.589(0.558)$ \\
\hline & No religion & $103.72 \pm 15.308$ & & $47.83 \pm 6.528$ & & $40.11 \pm 9.725$ & & $15.78 \pm 1.629$ & \\
\hline \multirow{2}{*}{$\begin{array}{l}\text { Number of } \\
\text { Children }\end{array}$} & 1 & $106.00 \pm 9.604$ & $0.549(0.585)$ & $49.67 \pm 5.053$ & $0.517(0.607)$ & $40.06 \pm 4.193$ & $-0.042(0.966)$ & $16.28 \pm 2.761$ & $1.528(0.140)$ \\
\hline & $\geq 2$ & $104.17 \pm 12.607$ & & $48.83 \pm 5.991$ & & $40.15 \pm 8.610$ & & $15.20 \pm 1.792$ & \\
\hline \multirow{2}{*}{$\begin{array}{l}\text { Employment } \\
\text { status }\end{array}$} & Employed & $112.10 \pm 9.689$ & $2.258(0.028)$ & $52.20 \pm 4.756$ & $1.944(0.057)$ & $42.60 \pm 4.575$ & $1.151(0.255)$ & $17.30 \pm 1.947$ & $3.034(0.004)$ \\
\hline & Non-employed & $103.22 \pm 11.609$ & & $48.45 \pm 5.697$ & & $39.61 \pm 7.908$ & & $15.16 \pm 2.045$ & \\
\hline \multirow{2}{*}{$\begin{array}{l}\text { Monthly } \\
\text { income }\end{array}$} & $<4$ million & $103.75 \pm 10.042$ & $-0.757(0.452)$ & $48.63 \pm 4.187$ & $-0.560(0.580)$ & $39.72 \pm 7.314$ & $-0.566(0.574)$ & $15.41 \pm 2.061$ & $-0.484(0.631)$ \\
\hline & $\geq 4$ million & $106.14 \pm 12.897$ & & $49.48 \pm 6.088$ & & $40.95 \pm 8.411$ & & $15.71 \pm 2.552$ & \\
\hline \multirow{2}{*}{ Housing } & Own house & $105.66 \pm 13.573$ & $0.590(0.558)$ & $49.17 \pm 6.709$ & $0.115(0.909)$ & $40.72 \pm 7.995$ & $0.606(0.547)$ & $15.76 \pm 2.325$ & $0.810(0.421)$ \\
\hline & Other & $103.83 \pm 9.756$ & & $49.00 \pm 4.616$ & & $39.53 \pm 7.080$ & & $15.30 \pm 2.020$ & \\
\hline \multirow{2}{*}{$\begin{array}{l}\text { Information } \\
\text { from health } \\
\text { care provider }\end{array}$} & $\begin{array}{l}\text { Health care } \\
\text { provider }\end{array}$ & $101.95 \pm 10.519$ & $-2.568(0.013)$ & $47.92 \pm 5.237$ & $-2.180(0.033)$ & $38.45 \pm 7.195$ & $-2.394(0.020)$ & $15.58 \pm 1.954$ & $0.253(0.801)$ \\
\hline & Others & $109.76 \pm 12.345$ & & $51.19 \pm 5.997$ & & $43.14 \pm 7.248$ & & $15.43 \pm 2.561$ & \\
\hline \multirow{2}{*}{ Age of child } & $2-3 y r s$ & $104.71 \pm 14.125$ & $-0.007(0.994)$ & $48.81 \pm 6.282$ & $-0.274(0.785)$ & $40.62 \pm 10.893$ & $0.310(0.759)$ & $15.29 \pm 2.327$ & $-0.628(0.533)$ \\
\hline & $4-6$ yrs & $104.74 \pm 10.368$ & & $49.24 \pm 5.420$ & & $39.84 \pm 4.885$ & & $15.66 \pm 2.096$ & \\
\hline \multirow{2}{*}{ Gender } & Male & $104.71 \pm 11.473$ & $-0.011(0.991)$ & $49.51 \pm 5.948$ & $0.697(0.489)$ & $39.74 \pm 7.326$ & $-0.461(0.646)$ & $15.46 \pm 2.119$ & $-0.290(0.773)$ \\
\hline & Female & $104.75 \pm 12.323$ & & $48.46 \pm 5.357$ & & $40.67 \pm 7.878$ & & $15.63 \pm 2.281$ & \\
\hline \multirow{2}{*}{ Sibling } & Yes & $104.17 \pm 12.607$ & $-0.549(0.585)$ & $48.83 \pm 5.991$ & $-0.517(0.607)$ & $40.15 \pm 8.610$ & $0.042(0.966)$ & $15.20 \pm 1.792$ & $1.528(0.140)$ \\
\hline & No & $106.00 \pm 9.604$ & & $49.67 \pm 5.053$ & & $40.06 \pm 4.193$ & & $16.28 \pm 2.761$ & \\
\hline \multirow{2}{*}{ Diagnosis } & Leukemia & $105.92 \pm 8.980$ & $0.692(0.492)$ & $49.12 \pm 4.744$ & $0.036(0.971)$ & $41.62 \pm 6.579$ & $1.371(0.176)$ & $15.19 \pm 2.020$ & $-1.048(0.299)$ \\
\hline & Solid cancer & $103.79 \pm 13.562$ & & $49.06 \pm 6.413$ & & $38.94 \pm 8.058$ & & $15.79 \pm 2.274$ & \\
\hline \multirow{2}{*}{$\begin{array}{l}\text { Time since } \\
\text { diagnosis }\end{array}$} & $<1 \mathrm{yr}$ & $103.62 \pm 12.841$ & $-0.644(0.522)$ & $49.00 \pm 5.650$ & $-0.101(0.920)$ & $39.27 \pm 10.094$ & $-0.769(0.445)$ & $15.35 \pm 2.097$ & $-0.560(0.577)$ \\
\hline & $\geq 1$ year & $105.61 \pm 10.880$ & & $49.15 \pm 5.810$ & & $40.79 \pm 4.622$ & & $15.67 \pm 2.245$ & \\
\hline \multirow{2}{*}{ Relapse } & Yes & $104.64 \pm 13.258$ & $-0.031(0.975)$ & $47.71 \pm 6.832$ & $-1.032(0.306)$ & $40.86 \pm 9.272$ & $0.419(0.677)$ & $16.07 \pm 2.235$ & $1.080(0.285)$ \\
\hline & No & $104.76 \pm 11.364$ & & $49.51 \pm 5.303$ & & $39.89 \pm 6.968$ & & $15.36 \pm 2.144$ & \\
\hline \multirow{2}{*}{$\begin{array}{c}\text { Duration of } \\
\text { treatment }\end{array}$} & $<1 \mathrm{yr}$ & $103.50 \pm 13.02$ & $-0.763(0.449)$ & $48.82 \pm 5.945$ & $-0.335(0.739)$ & $39.21 \pm 9.792$ & $-0.878(0.383)$ & $15.46 \pm 2.134$ & $-0.204(0.839)$ \\
\hline & $\geq 1$ year & $105.84 \pm 10.504$ & & $49.32 \pm 5.540$ & & $40.94 \pm 4.589$ & & $15.58 \pm 2.233$ & \\
\hline
\end{tabular}




\subsection{Relationships among Maternal Uncertainty, Perceived Social Support, and Maternal Coping}

Table 6 shows a statistically significant negative relationship between maternal uncertainty and maternal coping in mothers of children with cancer $(r=-0.398, p=0.002)$. There was a statistically significant moderate and positive relationship between perceived social support and maternal coping in mothers of children with cancer $(\mathrm{r}=$ 0.527, $\mathrm{p}=0.000)$.

\subsection{Factors Affecting Maternal Coping}

After testing the assumption of regression analysis, it was found that all of the assumptions were acceptable. Hierarchical multiple regression analysis was performed to identify the main factors affecting maternal coping in mothers of children with cancer. The model included maternal uncertainty, perceived social support, and general variables, such as maternal employment status, and sources of information, that were significantly related to maternal coping in the prior analyses (Table 7). The results indicated that maternal uncertainty and perceived social support were significant predictors of maternal coping in mothers of children with cancer. Maternal uncertainty and perceived social support together explained $35 \%$ of the variance in the maternal coping in mothers of children with cancer $\left(R^{2}=0.353, F=15.255, \mathrm{p}=0.000\right)$. The regression coefficients of maternal uncertainty and perceived social support were $-0.283(t=-2.544, \mathrm{p}=$ $0.014)$ and $0.455(t=4.097, \mathrm{p}=0.000)$, respectively (Figure 2$)$.

\section{Discussion}

The present study examined factors that affect maternal coping in Korean mothers of children with cancer. The present findings contribute to the ability to predict and understand maternal coping in mothers of children with cancer. According to the UIT, uncertainty and social support are the major factors that determine a parent's coping. In the present study, maternal uncertainty and perceived social support predicted maternal coping in mothers of children with cancer. Maternal uncertainty and perceived

Table 6. Pearson's product moment correlation between maternal uncertainty, perceived social support and maternal coping in mothers of children with cancer $(N=59)$.

\begin{tabular}{|c|c|c|c|}
\hline Variables & Maternal Uncertainty & Perceived Social Support & Maternal Coping \\
\hline Maternal Coping & $-0.398^{* *}$ & $0.527^{* *}$ & \\
\hline Maternal Coping (Effort for optimistic definition of the situation) & $-0.565^{\star \star}$ & $0.594^{* *}$ & $0.762^{* *}$ \\
\hline Maternal Coping (Effort to resolve the problem) & -0.132 & $0.407^{* *}$ & $0.526^{* *}$ \\
\hline
\end{tabular}

${ }^{*} \mathrm{p}<0.05,{ }^{* *} \mathrm{p}<0.01$. 
Table 7. A hierarchical multiple regression of maternal uncertainty and perceived social support with maternal coping in mothers of children with cancer $(N=59)$.

\begin{tabular}{cccccc}
\hline Variables & $\mathrm{B}$ & $\beta$ & $t(p)$ & $R^{2}$ & $F(p)$ \\
\hline Maternal uncertainty & -0.334 & -0.283 & $-2.544(0.014)$ & 0.353 & $15.255(0.000)$ \\
Perceived social support & 0.846 & 0.455 & $4.097(0.000)$ & & \\
\hline
\end{tabular}

Adjusted $\mathrm{R}^{2}=0.387$.

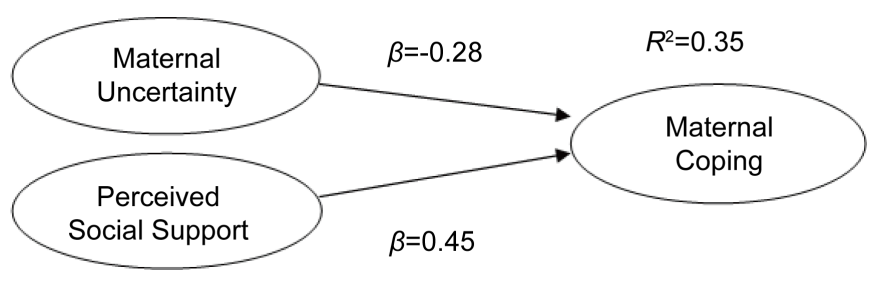

Figure 2. Regression coefficients and multiple correlations of maternal uncertainty and perceived social support maternal coping in mothers of children with cancer.

social support together explained $35 \%$ of the variance in the maternal coping. The results are also consistent with other studies among different populations [20] [38]-[40].

It was found that maternal uncertainty had a significant effect on maternal coping in mothers of children with cancer. The regression coefficient of maternal uncertainty was $-0.283(t=-2.544, \mathrm{p}=0.014)$, indicating that uncertainty is a stressor for Korean mothers of children with cancer, which puts these mothers at a greater risk for negative maternal coping. This result is consistent with the theory stating that uncertainty in illness is the inability to determine the meaning of illness-related events; this occurs in situations where the decision-maker is unable to assign a definite value to objects or events or is unable to predict an outcome due to a lack of sufficient cues [21]. The results are also consistent with other studies that were conducted with diverse populations. Lin Lin [41] found that lower parental uncertainty was associated with improved parental coping in Taiwanese parents of children with cancer. Moreover, a study by Madeo et al. [42] indicated that when parents perceive greater uncertainty, they perceive less control over their child's condition. Furthermore, Sterken [20] found that parents' perceptions of uncertainty were significantly related to fathers' coping styles. A study of Lipinski et al. [43] found that uncertainty was an independent predictor of parental coping and the regression coefficient of uncertainty was 0.20 ( $\mathrm{SE}=0.070, \mathrm{p}=$ 0.004). The results of the present study are not consistent with a study by Lee et al. which found that uncertainty did not significantly predict distress [44]. Tak and McCubbin also found a non-significant direct effect between family stress and coping among mothers of children with congenital heart disease [39].

Perceived social support, as defined in this study, was the mother's perception as to whether she received adequate support from family, friends and significant others. Thus, if a mother perceived greater social support, she might also be likely to report a higher level of coping. In the present study, perceived social support significantly con- 
tributed to maternal coping in Korean mothers of children with cancer. The magnitude of perceived social support coefficient was $0.455(t=4.097, \mathrm{p}=0.000)$. The soundness of the conceptual model of maternal coping in mothers of children with cancer derived from Mishel's uncertainty in illness theory was supported by the present study. The result is consistent with those from previous studies. A study found that maternal perceived social support significantly contributed to the prediction of maternal coping in mothers of children with congenital heart disease $(\beta=0.39, \mathrm{p}=0.000)$, accounting for $15 \%$ of the variance [39]. Han found a significant relationship between perceived social support and coping in mothers of children with cancer $(r=0.48, p<0.000)$ [29]. Beltrao et al. indicated that mothers perceived that support from their family members, health care team, and friends helped them cope with their children's disease and its effects [45]. Another study found that parents of children with life-threatening and nonlife-threatening illnesses reported significant differences in social support and coping behavior [46]. Lee et al. found that social support explained 33.3\% of parenting stress [25]. Study of Tak and McCubbin indicated that interventions should be directed at enhancing social support, as there is empirical evidence that perceived social support is a predictor of family coping [39].

\subsection{Implications for Nursing Practice}

Nurses can provide informational and emotional support to mothers, as mothers need support in coping with the constant uncertainty of the illness-related situation.

\subsection{Implication for Future Studies}

Further studies are necessary to explain the causal relationships among the UIT variables. An intervention design also may help mothers feel more support and less uncertainty.

\subsection{Limitations}

A measurement error was likely to have influenced the results. Regarding answering the item of monthly income, the participants were rigid to answer this question. In addition, the questionnaire was missing an item regarding marital status, which may contribute to maternal coping. In terms of generalizability, the subjects were limited to mothers of children with cancer admitted in to a specialized Korean hospital.

\section{Conclusion}

This study demonstrated the implication of the Mishel's UIT in examining factors affecting maternal coping in mothers of children with cancer. The findings indicated that maternal uncertainty and perceived social support were significant determinants of maternal coping. Therefore, it is suggested that nurses actively participate in facilitating information and provide support to mothers. Providing support may alleviate uncertainty and assist mothers in coping with the diagnosis and treatment of their children. Mothers need information about what is happening and what to expect before and after 
treatment, and advice and encouragement that change the level of uncertainty and improve maternal coping when their children are diagnosed with and receiving treatment for cancer.

\section{References}

[1] American Cancer Society (2015) Global Cancer Facts \& Figures. 3rd Edition, American Cancer Society, Atlanta.

[2] Ferlay, J., Soerjomataram, I., Ervik, M., Dikshit, R., Eser, S., Mathers, C., et al. (2012) Cancer Incidence and Mortality Worldwide: IARC Cancer Base No. 11. GLOBOCAN, 1.

[3] Korean Ministry of Health \& Welfare (KMHW) (2008) Annual Report of Cancer Incidence (2005) and Survival (1993-2005). KACLA, Korea.

[4] World Bank Group (2016) World Development Indicators 2016. International Bank for Reconstruction and Development, Washington DC.

[5] Hossain, M.S., Begum, M., Mian, M.M., Ferdous, S., Kabir, S., Sarker, H.K., et al. (2016) Epidemiology of Childhood and Adolescent Cancer in Bangladesh, 2001-2014. BioMed Central Cancer, 16, 104. http://dx.doi.org/10.1186/s12885-016-2161-0

[6] Marcus, J. (2012) Psychosocial Issues in Pediatric Oncology. The Ochsner Journal, 12, 211-215.

[7] Theofanidis, D. (n.d.) Chronic Illness in Childhood: Psychosocial Adaptation and Nursing Support for the Child and Family. Health Science Journal, 2, 1-9.

[8] McCaffery, C.N. (2006) Major Stressors and Their Effects on the Well-Being of Children with Cancer. Journal of Pediatric Nursing, 21, 59-66. http://dx.doi.org/10.1016/j.pedn.2005.07.003

[9] UICC (2006) Childhood Cancer: Rising to the Challenge. The International Union.

[10] Boman, K.K., Viksten, J., Kogner, P. and Samuelsson, U. (2004) Serious Illness in Childhood: The Different Threats of Cancer and Diabetes from a Parent Perspective. Journal of Pediatrics, 145, 373-379.

[11] Martinson, I.M., Kim, S., Yang, S.O., Cho, Y.S., Lee, J.S. and Lee, Y.H. (1995) Impact of Childhood Cancer on Korean Families. Journal of Pediatric Oncology Nursing, 12, 11-17.

[12] Mu, P.F., Ma, F.C., Ku, S.M., Shu, H.Q., Hwang, B. and Kuo, B.I. (2001) Families of Chinese children with Malignancy: The Factors Impact on Mother's Anxiety. Journal of Pediatric Nursing, 16, 287-295. http://dx.doi.org/10.1053/jpdn.2000.25325

[13] Barrera, M., D’Agostino, N.M., Gibson, J., Gilbert, T., Weksberg, R. and Malkin, D. (2004) Predictors and Mediators of Psychological Adjustment in Mothers of Children Newly Diagnosed with Cancer. Psycho-Oncology, 13, 630-641. http://dx.doi.org/10.1002/pon.765

[14] Klassen, A.F., Klaassen, R., Dix, D., Pritchard, S., Yanofsky, R., O’Donnell, M., et al. (2008) Impact of Caring for a Child with Cancer on Parents' Health-Related Quality of Life. Journal of Clinical Oncology, 26, 5884-5889. http://dx.doi.org/10.1200/jco.2007.15.2835

[15] Eun-Sook P, Won-Oak O, Min-Hyun S, Young-Mi Y. (2009) From Their Own Response: Experiences of Korean Children with Chronic Illness and Their Families. Journal of Korean Academy of Child Health Nursing, 15, 350-358. http://dx.doi.org/10.4094/jkachn.2009.15.4.350

[16] Nelson, A.E., Miles, M.S. and Belyea, M.J. (1997) Coping and Social Support Effects on Mothers' Stress Responses to Their Child's Hematopoietic Stem Cell Transplantation. Journal of Pediatric Oncology Nursing, 14, 202-212. 
[17] Basher, M., Karim, M., Sultana, N. and Hossain, K.J. (2012) Parent Stress in Childhood Cancer. Bangladesh Medical Journal, 41, 8-13.

[18] Barbarin, O.A. and Chesler, M. (1986) The Medical Context of Parental Coping with Childhood Cancer. American Journal of Community Psychology, 14, 221-235. http://dx.doi.org/10.1007/BF00911822

[19] Pelletier-Hibbert, M. and Sohi, P. (2001) Sources of Uncertainty and Coping Strategies Used by Family Members of Individuals Living with End Stage Renal Disease. Nephrology Nursing Journal, 28, 411-419.

[20] Sterken, D. (1996) Uncertainty and Coping in Fathers of Children with Cancer. Journal of Pediatric Oncology Nursing, 13, 81-88.

[21] Mishel, M. (1988) Uncertainty in Illness. Journal of Nursing Scholarship, 20, 225-232. http://dx.doi.org/10.1111/j.1547-5069.1988.tb00082.x

[22] Bowers, R.J. (2006) Uncertainty and Social Support as Predictors of Coping in Women Experiencing Fibromyoma: A Structural Model. Unpublished Doctoral Dissertation, Ball State University, Muncie.

[23] Cohen, M. and Martinson, I. (1988) Chronic Uncertainty: Its Effect on Parental Appraisal of Child's Health. Journal of Pediatric Nursing, 3, 89-96.

[24] Dodgson, J.E., Garwick, A., Blozis, S.A., Patterson, J.M., Bennett, F.C. and Blum, R.W. (2000) Uncertainty in Childhood Chronic Conditions and Family Distress of Young Children. Journal of Family Nursing, 6, 252-266. http://dx.doi.org/10.1177/107484070000600304

[25] Lee, S., Yoo, J.S. and Yoo, I.Y. (2007) Parenting Stress in Mothers of Children with Congenital Heart Disease. Asian Nursing Research, 1, 116-124. http://dx.doi.org/10.1016/S1976-1317(08)60014-6

[26] Speechley, K.N. and Noh, S. (1992) Surviving Childhood Cancer, Social Support and Parent's Psychological Adjustment. Journal of Pediatric Psychology, 17, 15-31. http://dx.doi.org/10.1093/jpepsy/17.1.15

[27] Kazak, A.E., Meeske, K., Penati, B., Barakat, L.P., Christakis, D., Meadow, A.T., et al. (1997) Posttraumatic Stress, Family Functioning and Social Support in Survivors of Childhood Leukemia and Their Parents. Journal of Consulting and Clinical Psychology, 65, 120-129. http://dx.doi.org/10.1037/0022-006X.65.1.120

[28] Sloper, P. (2000) Predictors of Distress in Parents of Children with Cancer: A Prospective Study. Journal of Pediatric Psychology, 25, 79-91. http://dx.doi.org/10.1093/jpepsy/25.2.79

[29] Han, H. (2003) Korean Mother's Psychological Adjustment to Their Children's Cancer. Journal of Advanced Nursing, 44, 499-506. http://dx.doi.org/10.1046/j.0309-2402.2003.02833.x

[30] Han, H., Cho, E.J., Kim, D. and Kim, J. (2009) The Report of Coping Strategies and Psychosocial Adjustment in Korean Mothers of Children with Cancer. Psycho-Oncology, 18, 956-964. http://dx.doi.org/10.1002/pon.1514

[31] Wijnberg-Williams, B.J., Kamps, W.A., Klip, E.D.C. and Hoekstra-Weebers, J.E.H.M. (2006) Psychological Adjustment of Parents of Pediatric Cancer Patients Revisited: Five Years Later. Psycho-Oncology, 15, 1-8. http://dx.doi.org/10.1002/pon.927

[32] Mishel, M.H. (1983) Parents' Perception of Uncertainty Concerning Their Hospitalized Child. Nursing Research, 32, 324-330. http://dx.doi.org/10.1097/00006199-198311000-00002

[33] Zimet, G.D. and, Zimet, S.D. and Farley, S.G. (1988) The Multidimensional Scale of Perceived Social Support. ¡Journal of Personality Assessment, 52, 30-41. 
http://dx.doi.org/10.1207/s15327752jpa5201_2

[34] Canty-Mitchell, J. and Zimet, G.D. (2000) Psychometric Properties of the Multidimensional Scale of Perceived Social Support in Urban Adolescents. American Journal of Community Psychology, 28, 391-400. http://dx.doi.org/10.1023/A:1005109522457

[35] Kim, J.H. (2008) College Adjustment of Adult Children of Alcoholics. Unpublished Doctoral Dissertation, Seoul Women's University Graduate School, Seoul.

[36] McCubbin, M.A. and McCubbin, H.I. (1983) Family Coping with Health Crisis: The Resiliency Model of Family Stress, Adjustment and Adaptation. Mosby, St. Louis.

[37] Kang, H.S., Yeom, S.Y. and Jun, E.-Y. (2013) Effect of Intervention Programs for Improving Maternal Adaptation in Korea: Systematic Review. Korean Journal of Women Health Nursing, 19, 153-165. http://dx.doi.org/10.4069/kjwhn.2013.19.3.153

[38] Grootenhuis, M.A. and Last, B.F. (1997) Adjustment and Coping by Parents of Children with Cancer: A Review of the Literature. Supportive Care in Cancer, 5, 466-484. http://dx.doi.org/10.1007/s005200050116

[39] Tak, Y.R. and McCubbin, M. (2002) Family Stress, Perceived Social Support and Coping Following the Diagnosis of a Child's Congenital Heart Disease. Journal of Advanced Nursing, 39, 190-198. http://dx.doi.org/10.1046/j.1365-2648.2002.02259.x

[40] Vasundhara, K., Gupta, V., Piplani, K.S., Bhatia, B.D. and Upadhayay, S.K. (2011) Parental Stress and Coping Techniques in Parents of Children with Bronchial Asthma. Indian Journal of Allergy, Asthma and Immunology, 25, 103-108.

[41] Lin, L., Yeh, C.H. and Mishel, M.H. (2010) Evaluation of a Conceptual Model Based on Mishel's Theories of Uncertainty in Illness in a Sample of Taiwanese Parents of Children with Cancer: A Cross-Sectional Questionnaire Survey. International Journal of Nursing Studies, 47, 1510-1524. http://dx.doi.org/10.1016/j.ijnurstu.2010.05.009

[42] Madeo, A.C., O’Brien, K.E., Bernhardt, B.A. and Biesecker, B.B. (2012) Factors Associated with Perceived Uncertainty among Parents of Children with Undiagnosed Medical Conditions. American Journal of Medical Genetics Part A, 158A, 1877-1884. http://dx.doi.org/10.1002/ajmg.a.35425

[43] Lipinski, S.E., Lipinski, M.J., Biesecker, L.G. and Biesecker, B.B. (2006) Uncertainty and Perceived Personal Control among Parents of Children with Rare Chromosome Conditions: The Role of Genetic Counseling. American Journal of Medical Genetics Part C: Seminars in Medical Genetics, 142C, 232-240. http://dx.doi.org/10.1002/ajmg.c.30107

[44] Lee, H., Schepp, K.G. and Jung, Y. (2008) Testing a Theoretical Model Predicting Uncertainty and Depression in Patients Undergoing Renal Replacement Therapy in Korea. Asian Nursing Research, 2, 92-101. http://dx.doi.org/10.1016/S1976-1317(08)60033-X

[45] Beltrao, M.R., Vasconcios, M.G.L., Pontes, C.M. and Albuquerque, M.C. (2007) Childhood Cancer: Maternal Perceptions and Strategies for Coping with Diagnosis. Jornal de Pediatria, 83, 562-566. http://dx.doi.org/10.2223/JPED.1723

[46] Katz, S. (2002) When the Childs Illness Is Life Threatening: Impact on the Parents. Pediatric Nursing, 28, 453-463. 
Submit or recommend next manuscript to SCIRP and we will provide best service for you:

Accepting pre-submission inquiries through Email, Facebook, LinkedIn, Twitter, etc. A wide selection of journals (inclusive of 9 subjects, more than 200 journals)

Providing 24-hour high-quality service

User-friendly online submission system

Fair and swift peer-review system

Efficient typesetting and proofreading procedure

Display of the result of downloads and visits, as well as the number of cited articles

Maximum dissemination of your research work

Submit your manuscript at: http://papersubmission.scirp.org/

Or contact ojn@scirp.org 